\title{
The Use of Anatomical Characteristics of The Stems in The Identification of Five Cultivars of Italian Pear Plant (Pyruscommunis L.) Cultivated in The North of Iraq
}

\author{
Amina A.Y. Dalalbashi \\ Department of Biology- Girls Education College \\ Mosul University \\ Amina.dalalbashi@gmail.com \\ DOI: $\underline{10.33899 / \text { edusj.1970.163330 }}$
}

Received

27/ 03 / 2019
Accepted

08 / 07 / 2019

\begin{abstract}
This research included a taxonomic study of pears plant using the anatomical characteristics of the stems of five cultivars of the Pyrus communis L. imported from Italy and implanted in Iraq (Beurre hardy, Conference, Bonne louise, Abate fetel, Doyenne comice). The cultivars were compared anatomically. The results showed significant differences for many of the anatomical characters including: The thickness and shape of the cross section of the stems, as well as the thickness and type of the bronchimic and collagenic tissue, as well as the thickness and shape of the phloem and xylem, and the number of vascular bundles. These important taxonomic variations played an important role in the isolation and identification cultivars.
\end{abstract}

Keywords: Pear, Anatomical Characteristics, Pyrus communis L. 


\title{
استخدام الصفات التشريحية للسيقان في تثخيص خمسة أصناف من نبات الكمثرى الإيطالية Pyrus communis L.
}

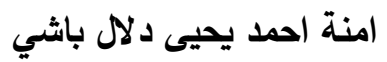 \\ قسم علوم الحياة / كلية التربية للبنات /جامعة الموصل \\ Amina.dalalbashi@gmail.com \\ DOI: 10.33899/edusj.1970.163330 \\ القبول \\ 2019 / 07 / 08 \\ الاستلام \\ 2019 / $03 / 27$
}

\section{الخلاصة}

تضمن هذا البحث دراسة تصنيفية باستعمال الخصائص التثريحية لسيقان خمسة أصناف من نبات الكثرى

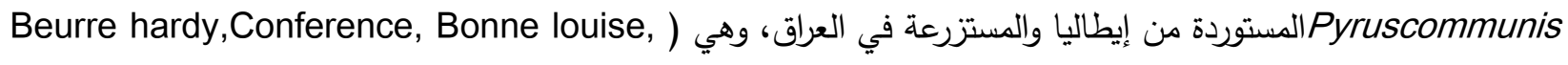
Abate fetel, Doyenne comice ) الصفات التشريحية وشملت كلُ من شكل المقطع المستعرض للساق، سمك البشرة،الكساء السطحي للساق،سكك القشرة وشكلها، إضافة إلى سمك النسيج البرنكيمي والكولنكيمي ونوعه، وأيضا سمك اللحاء والخشب وشكلة، وعدد الحزم الوعائية،ققد لوحظ التطاء العديد من التغايرات المهمة تصنيفياً التي لها أهمية في عزل وتثخيص الكيكي الأصناف المدروسة.

الكلمات المفتاحية: الكثرى، الصفات التشريحية، Pyrus communisL . 


\section{المقدمة}

إن علم تصنيف النبات من العلوم المهمة الذي وضع حدوداً دقيقة وواضحة إذ من المكن فصل أي مرتبة تصنيفية عن غيرها، ولقد اتسعت الدراسات التصنيفية وتحولت من خصائص واضحة للعيان الى استعمال خصائص أكثر تعقيداً، منها الخصائص التشريحية التي ساهمت مساهمة فعالة في تصنيف النباتات، وفي معرفة العلاقات التطورية بين النباتات [1]. إن التقدم الكبير الذي حصل في الدراسات التشريحية للنبات الذي اقترن بالوسائل العلمية المتقدمة، منها المجاهر الآكترونية والمجاهر الضوئية أدى إلى حل العديد من المشاكل التصنيفية المعقدة. وتعد الخصائص التشريحية مهمة لقلة تأثرها بالظروف البيئية]2]، كما ازداد اهتمام علماء التصنيف في مثل هذه الدراسات وتعمقوا بها لغرض إيجاد العديد من الصفات التي تساعد في فصل العديد من المراتب الثصنيفية منها الجنس والنوع والضرب[3]. ينتمي نبات الكمثرى .Pyrus communis إلى العائلة الوردية Rosaceae التابعة إلى رتبة Rosales وتضم العائلة عالميا حوالي 122 جنساً و3370 نوعاً. أما في العراق فتضم حوالي 19 جنساً و 43 نوعاً برياً ومستزرعاً]4].أن أفضل الأراضي لزراعة الكمثرى هي الأراضي الطينية الخفيفة الغنية بالعناصر الغذائية ، وتتنشر نباتات هذه العائلة عالمياً في المناطق المعتدلة منها تركيا، إيطاليا، اليونان، اسبانيا،هولندا، روسيا وغيرها ـ أما في العراق فتكون بشكلين أما أشجار أو شجيرات (صاعدة أو قائمة) ،وينتشر وجودها في المناطق الجبلية لاسيما في السليمانية وأربيل ودهوك (العمادية) والتي تعد من المراكز المهمة لانتشار الأنواع التابعة لهذ الجنس [5] و[6]. تعد الكمثرى نوعاً من أنواع الفاكهة المتميزة يكثر استهلاكها في فصل الصيف، فهي متميزة بأليافها الغنية التي تمنح الإنسان الحيوية والانتعاش، كما أن احتواءها على العديد من الألياف ومضادات الأكسدة تجعل منها فاكهة مهمة للجسم ،فهي تكسبه القوة والمناعة لمقاومة الكثير من الأمراض التي قد يتعرض لها[7] [8]. تهدف من هذه الدراسة إلى تشخيص خمسة أصناف من الكمثرى الإيطالية المستزروعة في العراق، والتعرف عليها من خلال مقارنة الصفات التشريحية للسيقان الخضرية.

\section{مواد وطرائق البحث}

تم الاعتماد في هذه الدراسة على العينات للساق التي جمعت من خلال الجولات الحقلية في محافظة أربيل شمالي العراق FARO والمستوردة من إيطاليا من شركة PIANTE FARO وتمت الدراسة التشريحية لسيقان الأفرع الجانبية الطرية للأصناف المدروسة باستخدام طريقة التقطيع اليدوي التي اعتمدها بعض الباحثون [9] و[10] وكما في النقاط التالية: 1.تم تقطيع الساق النباتي إلى قطع صغيرة تتراوح طول كل قطعة (4 -6)سم النقطة الواقعة في منتصف الساق تقريبا. 2. يقطع الساق للأفرع الطرية للكمثرى بوضع عمودي بين الإبهام والسبابة وقطعها باستخدام شفرة حادة الى قطع رقيقة جدا وبوضع مستوي إلى إن يتم الحصول على أرق مقطع مستعرض من الساق. 
3. تتقل الدقاطع إلى شرائح زجاجية (Slides) تحتوي على قطرات من صبغة السفرانين 1\% ثم تضاف عدة قطرات من الكحول الاثيلي 70\% لتخفيف الصبغة ثم يوضع الغطاء على الثريحة برفق.

4. ثم فحصها الجهر الضوئي المركب وصورت النماذج باستعمال كاميرا موبايل نوع Not 8 تحت قوة تكبير العدسة العينية .

\section{النتائج والمناقشة}

أوضحت الدراسة التشريحية أن سيقان أصناف نبات الكمثى تمتلك خصائص جيدة لعزل الأصناف، فقد تبين من خلال

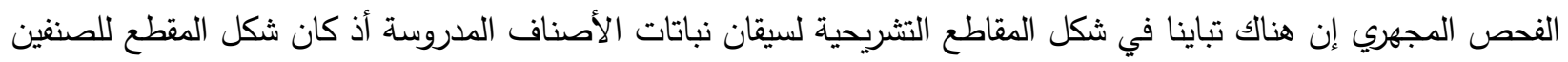

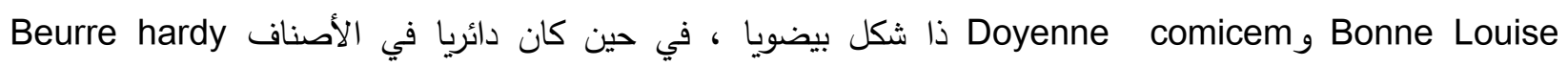
و Abate fetel Conference كما موضح في الجدول (1) لوحة (1)، فقد أظهرت هذه الصفة أهمية كبيرة في استخدامها لتصنيف النباتات لما لها من تغايرات واضحة بين الأصناف مما يجعلها صفات ذات قيمة تصنيفية كبيرة يمكن الاستفادة منها

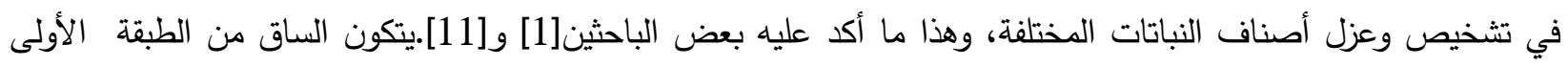
وهي البشرة Epidermis التي تميزت بصف واحد من الخلايا المتراصة مستطيلة الثكل ذات جدران مستقيمة في جميع لئي

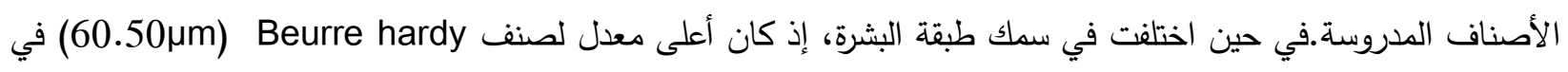

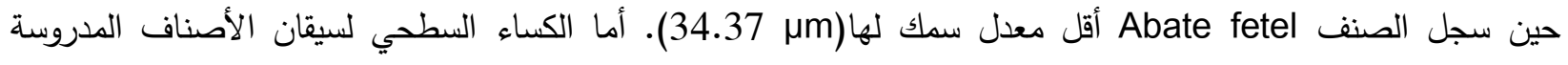

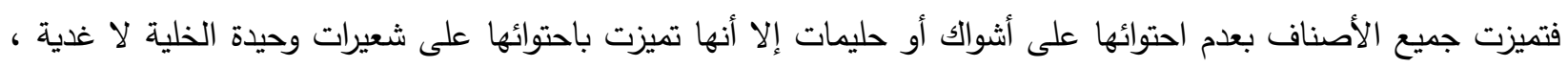

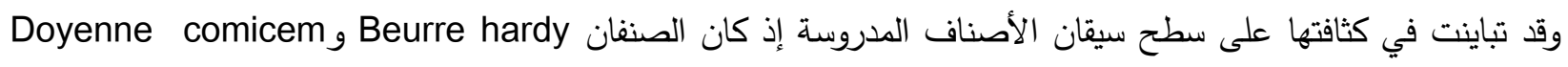
ذات شعيرات كثيفة في حين لوحظ أن الصنف Conference ذو شعيرات أقل كثافة ـ أما الصنفان Bonne Louise و Abatefetel فتميزت عن باقي الأصناف بعدم احتوائها على شعيرات أي أنها ملساء لوحة (2). وربما يعزى ذلك إلى سبب الكي

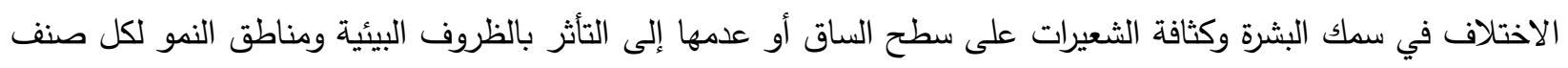

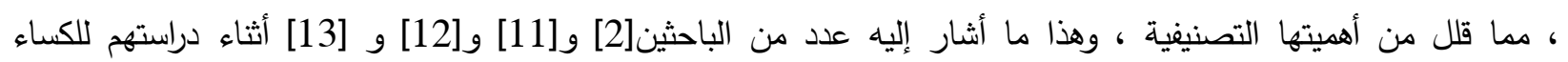
السطحي لنباتات مختلفة. 
استخام الصفات التثريحية للسيقان في تثخيص خمسة أصناف من نبات الكمثرى الإيطالية ...

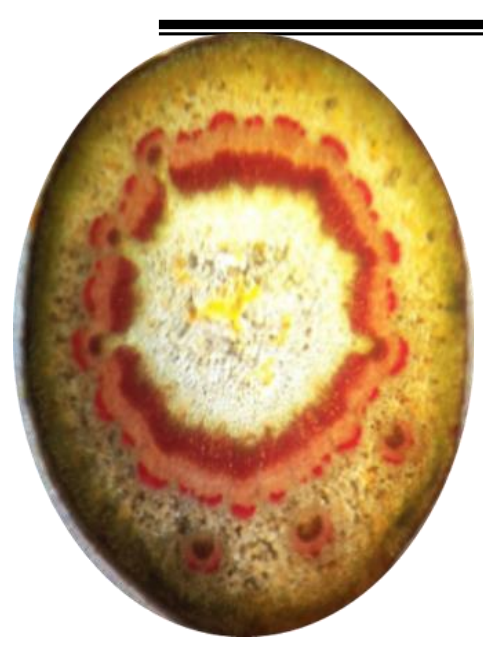

3onne Louise

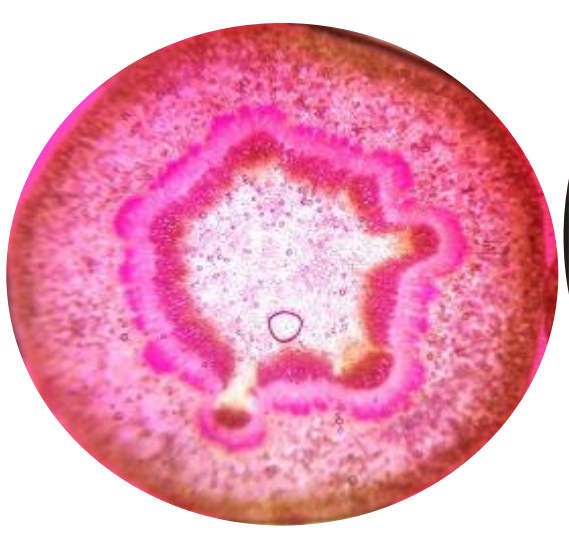

Conference 2.ئري 2

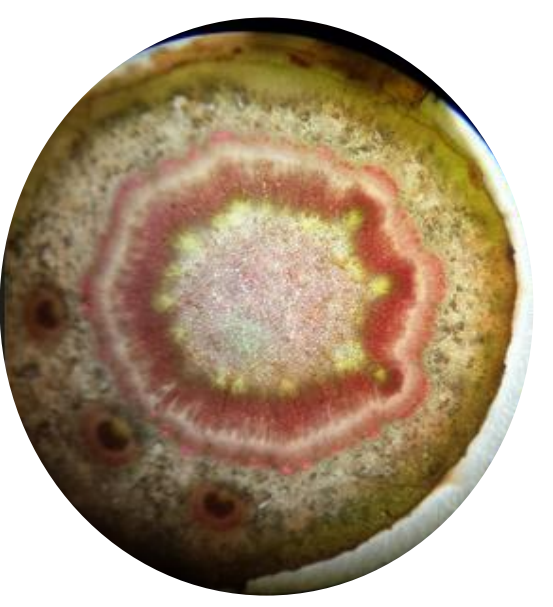

Beurre hardy 1

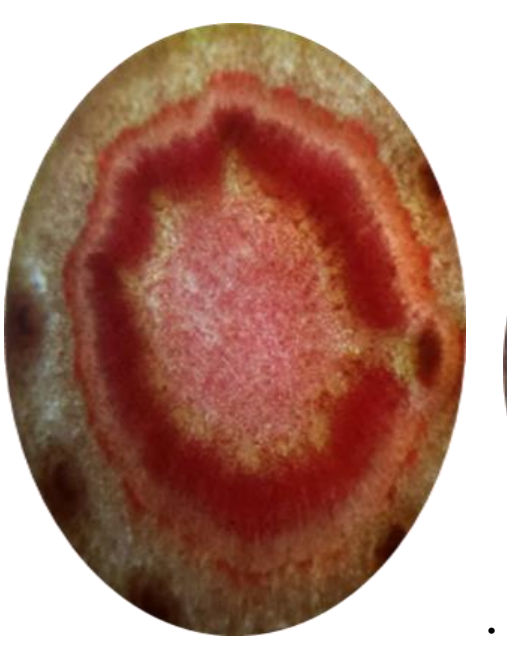

5oyenne comicem بيضوي

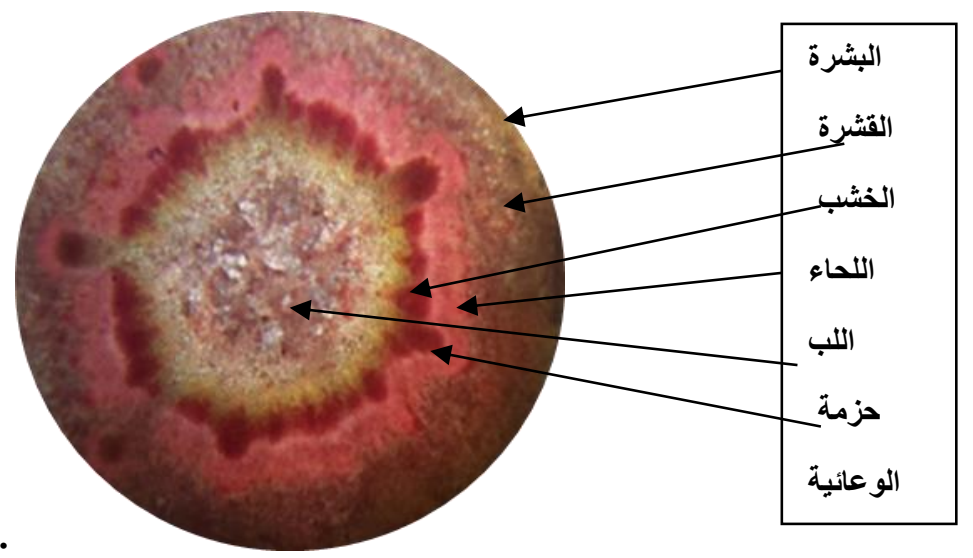

Abate fetel 4. 4.ئري

لوحة (1) مقطع عرضي لسيقان أصناف نبات الكمثرى (قوة تكبير 40) 
امنة احمد يحيى دلال باشي

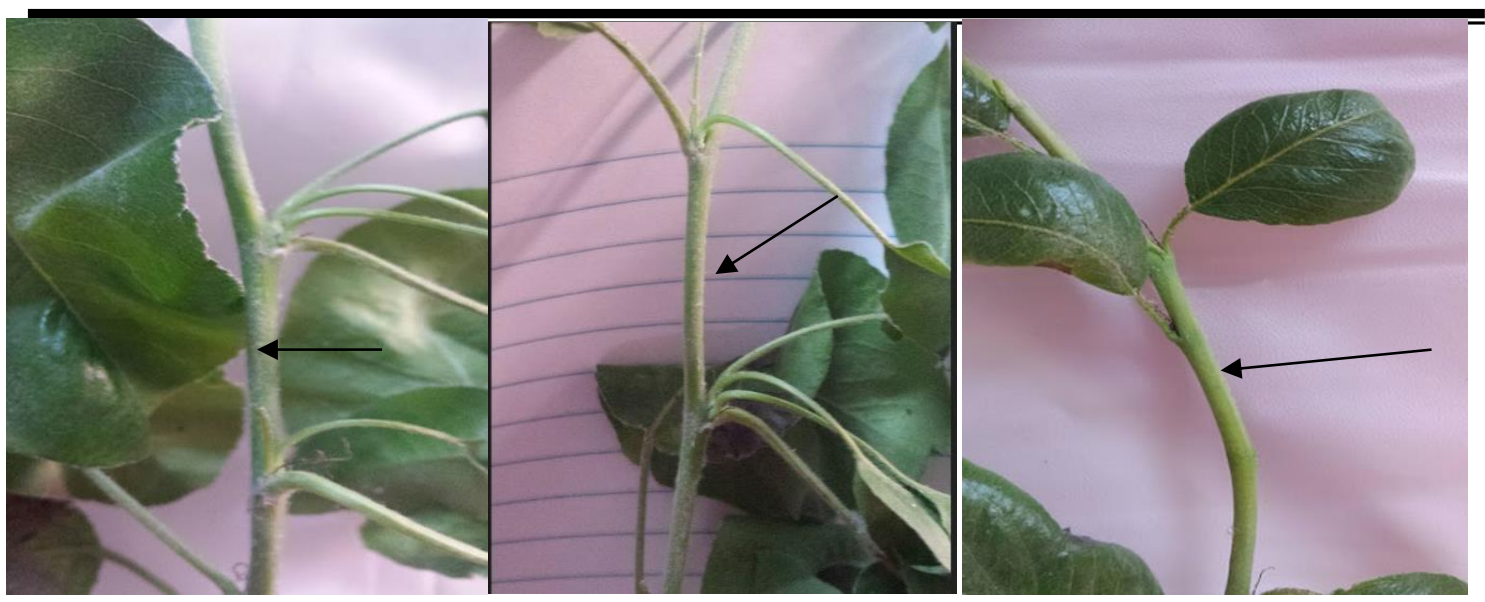

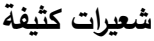

ملساء لا تحتوي على شعيرات

Bonne Louise

Abate Fetel conference
Beurre Hardy

Doyenre Comicem

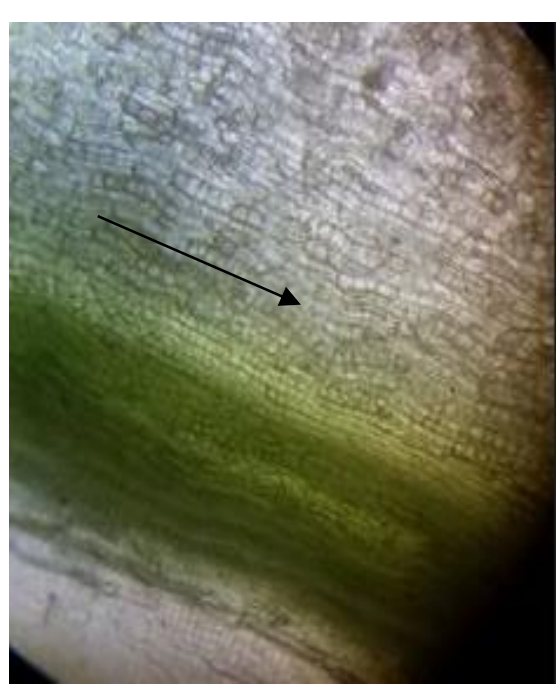

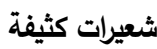
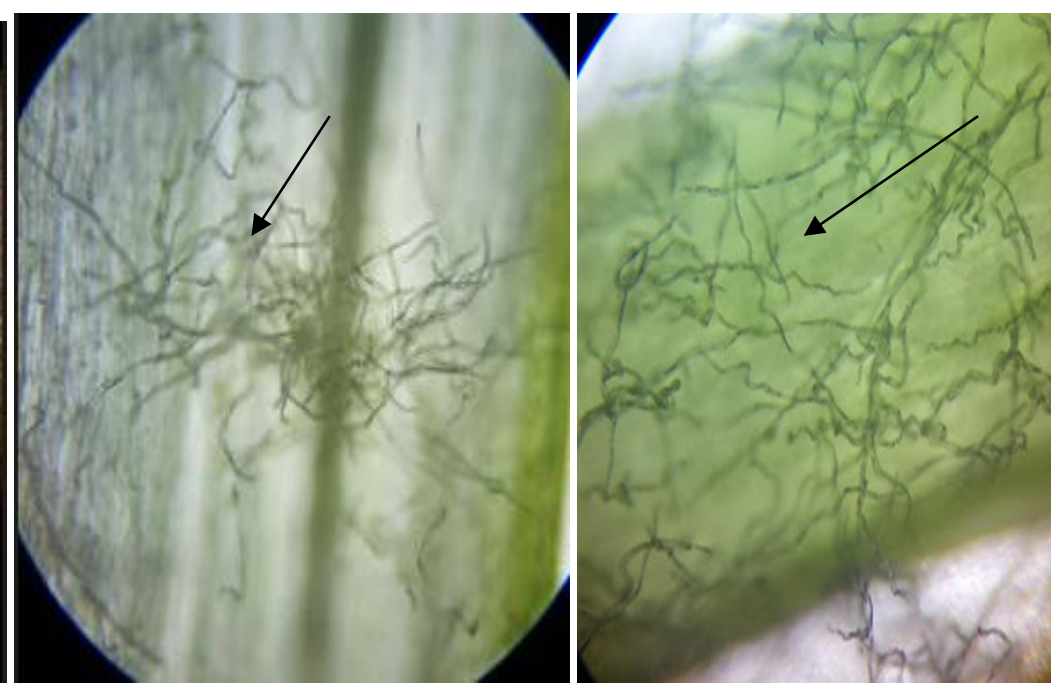

شعيرات قليلة

لوحة(2): كثافة الثعيرات على سطح الساق.

A (قوة تكبير 100) 
استخام الصفات التثريحية للسيقان في تثخيص خمسة أصناف من نبات الكمثى الإيطالية

جدول (1) الصفات النوعية والكمية للمقطع المستعرض في ساق أصناف الكمثرى قيد الاراسة مقاسة بالمايكروميتر .

\begin{tabular}{|c|c|c|c|c|c|c|c|c|c|}
\hline \multicolumn{3}{|c|}{ سمك قشرة الساق بالمايكرومتر } & \multirow{3}{*}{ 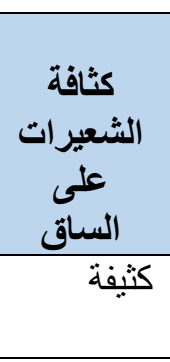 } & \multicolumn{3}{|c|}{$\begin{array}{c}\text { سمك البشرة للساق) } \\
\text { (مايكرومتر) }\end{array}$} & \multirow{2}{*}{ شكل المقطع } & \multicolumn{2}{|l|}{ الصفات } \\
\hline SD & المعدل & المدى & & SD & المعدل & المدى & & & \\
\hline 27.63 & 353.87 & $\begin{array}{r}-400 \\
310 \\
\end{array}$ & & 6.56 & 60.50 & $68-52$ & دائري & $\begin{array}{r}\text { Beurre } \\
\text { hardy }\end{array}$ & 1 \\
\hline 17.43 & 477.87 & $\begin{array}{r}-500 \\
450\end{array}$ & قليلة & 5.23 & 51.75 & $58-42$ & دائري & Conference & 2 \\
\hline 37.01 & 412.12 & $\begin{array}{r}-450 \\
350 \\
\end{array}$ & لا يوجد & 4.53 & 59.62 & $\begin{array}{r}66- \\
54 \\
\end{array}$ & بيضوي & $\begin{array}{c}\text { Bonne } \\
\text { Louise } \\
\end{array}$ & 3 \\
\hline 11.75 & 269.50 & $\begin{array}{r}-280 \\
250 \\
\end{array}$ & لا يوجد & 3.70 & 34.37 & $\begin{array}{r}40- \\
30 \\
\end{array}$ & دائري & Abate fetel & 4 \\
\hline 22.00 & 341.87 & $\begin{array}{r}-366 \\
300\end{array}$ & كثيفة & 3.81 & 45.5 & $51-40$ & بيضوي & $\begin{array}{l}\text { Doyenne } \\
\text { comicem }\end{array}$ & 5 \\
\hline
\end{tabular}

تلي طبقة البشرة Epidermis في الساق طبقة القشرة cortex التي تتكون من عدة صفوف، وقد اختلفت في سمكها بين

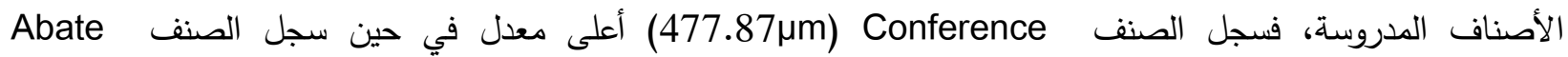
(269.50 بm)fetel أقل معدل لسمك القشرة، وقد شملت نوعين من الخلايا؛ خلايا كولنكيمية Collenchyma cell وخلايا بارنكيمية Parenchyma cell ، وتوجد الخلايا الكولنكيمية تحت طبقة البشرة مباشرة التي تمنح العضو النباتي الدعم والإسناد، وتباينت الخلايا الكولنكيمية بين الأصناف المدروسة إلى نوعين صفائحي في الأصناف Beurre hardy و و Donne Louise وفراغي في الصنفين Conference comiceme وكما تباين النسيج Abate fetel الكولنكيمي في سمكه إذ تراوح أعلى وأقل معدل للصنفين Conference و Dm Doyenne comicem 101.50)على التوالي. في حين سجلت الأصناف تغايراً في سمك النسيج البارنكيمي ،إذ تراوحت الأصناف بين أعلى وأقل

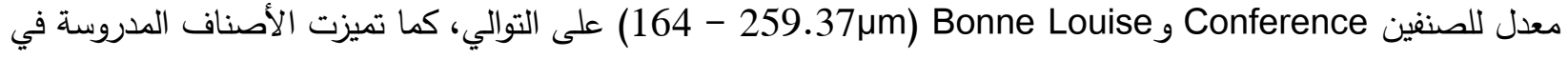
شeurre hardy شكل طبقة القشرة في وجود فراغات أو مسافات بينية بين خلاياها أو عدمها، إذ لوحظ أن الأصناف و Conference و بعدم وجود فراغات بين خلايا القشرة ،في حين لوحظ وجود فراغات بين خلايا القشرة في الصنفين Abate fetel Bonne Louise لوحة (3)، وهذا ما ينطبق مع ما ذكره بعض الباحثين[14] و[15] من خلال دراسة تشريحية لساق نبات البردي ونبات السعد على التوالي. 
جدول(2) : الصفات النوعية والكمية للنسيج الكولنكيمي والبرنكيمي في ساق أصناف الكمثرى (مقاسة بالميكروميتر).

\begin{tabular}{|c|c|c|c|c|c|c|c|c|c|}
\hline \multicolumn{3}{|c|}{ سمك النسيج البرنكيمي للساق } & \multirow[t]{2}{*}{ شكل طبقة } & \multirow{2}{*}{ الكوع لنكيميج } & \multicolumn{3}{|c|}{ سمك النسيج الكولنكيمي في } & \multirow{2}{*}{\multicolumn{2}{|c|}{ الصفات }} \\
\hline $\begin{array}{r}\text { SD } \\
\pm \\
\end{array}$ & المعدل & المدى & & & $\begin{array}{r}\text { SD } \\
\pm \\
\end{array}$ & المعدل & المدى & & \\
\hline 25.41 & 257.12 & $\begin{array}{r}300- \\
230\end{array}$ & صلد & صفائحي & 13.24 & $\begin{array}{r}127.3 \\
7\end{array}$ & $\begin{array}{r}-150 \\
110\end{array}$ & $\begin{array}{r}\text { Beurre } \\
\text { hardy }\end{array}$ & 1 \\
\hline 6.16 & 259.37 & $\begin{array}{r}270- \\
250 \\
\end{array}$ & صلد & صفائحي & 8.34 & $\begin{array}{r}143.3 \\
7\end{array}$ & $\begin{array}{r}-155 \\
130\end{array}$ & Conference & 2 \\
\hline 28.09 & 164 & $\begin{array}{r}200- \\
130\end{array}$ & فر اغتوي على & فر اغي & 13.59 & $\begin{array}{r}112.7 \\
5\end{array}$ & $90-130$ & $\begin{array}{l}\text { Bonne } \\
\text { Louise }\end{array}$ & 3 \\
\hline 16.59 & 174.62 & $\begin{array}{r}200- \\
150\end{array}$ & 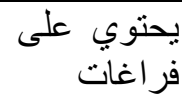 & فر اغي & 7.70 & $\begin{array}{r}122.6 \\
2\end{array}$ & $\begin{array}{r}-131 \\
110\end{array}$ & Abate fetel & 4 \\
\hline 24.71 & 255.62 & $\begin{array}{r}300- \\
220\end{array}$ & صلد & صفائحي & 9.79 & $\begin{array}{r}101.5 \\
0\end{array}$ & $90-120$ & $\begin{array}{l}\text { Doyenne } \\
\text { comicem }\end{array}$ & 5 \\
\hline
\end{tabular}

S.D

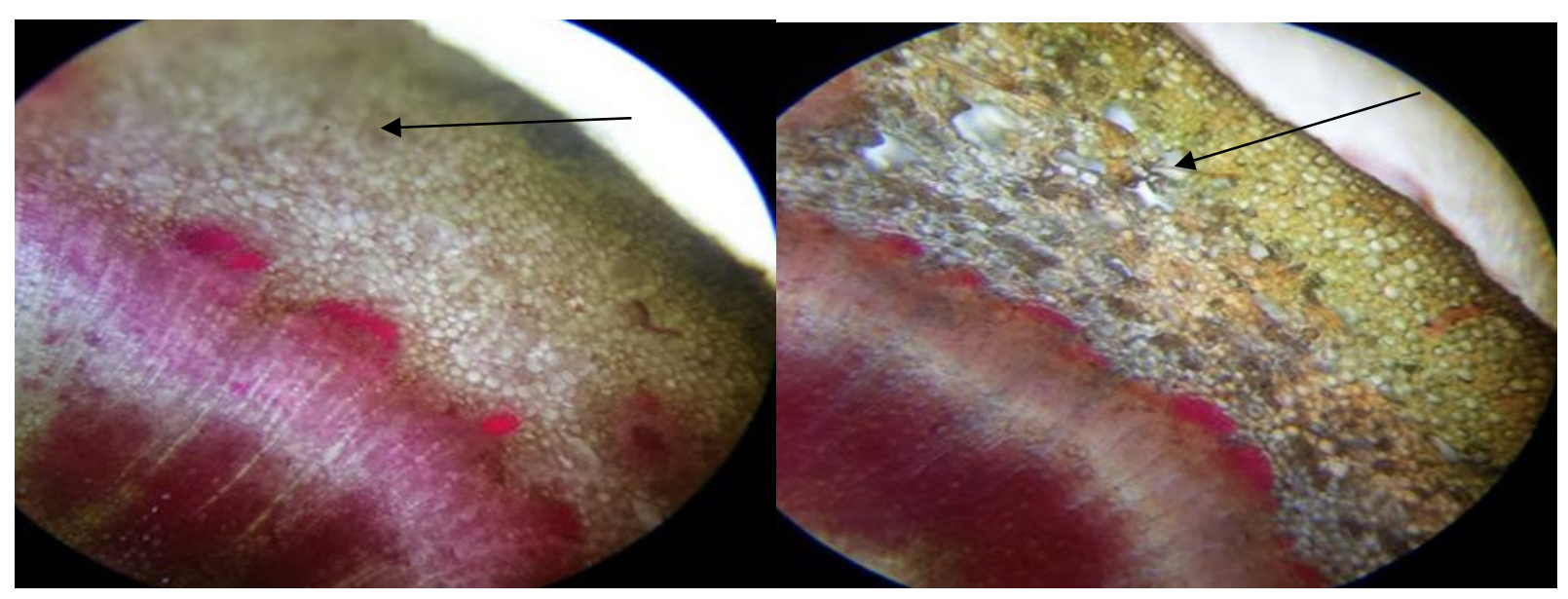

وجود مسافات بينية Bonne Louise

Abate fetel
Beurre Hardy علم وجود مسافات بينية

Conference

Doyenne Comicem

لوحة (3) مقطع لقشرة ساق نبات الكمثرى( قوه تكبير 100). 
أما الحزمة الوعائية Vascular bund لساق نبات الكمثرى فكانت من النوع الجانبي المفتوح ،لأن الخشب واللحاء على نصف قطر واحد (لوحة 1) ، ويكون اللحاء دائما للخارج والخشب للداخل،ويكون الخشب الأول للداخل والخشب التالي للخارج.وقد Abate fetel تباينت الأصناف المدروسة في شكل أوعية الخشب التالي ، إذ كان شكل الخشب التالي بيضويا في الصنفين و Doyenne comicem في حين كانت الأصناف Bourre hardy فو ذات شكل مضلع .كما اختلفت الأصناف في سمك الخشب xylem إذ تراوح أعلى وأقل معدل للصنفين Beurre hardy و 338.75 rm ) fetel سمك لحاء الساقphloem اذ كان اقل و أعلى معدل للصنفين ConferenceAbate fetel 275.87 و 120.62)وهذا يتماشى مع جاء به عدد من الباحثين [5]،[9]، [12] ، [16] إذ أكدوا على استخدام صفة سمك اللحاء لعدة نباتات للتميز بين الأنواع ـ أما مركز الساق فتسمى منطقة اللب pith ويتكون من عدة خلايا بارنكيمية كبيرة وجدرانها رقيقة

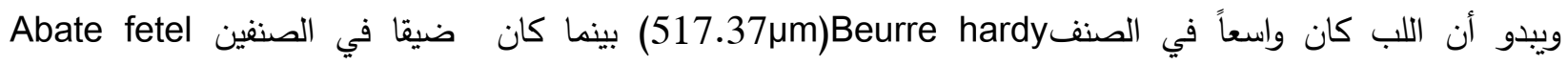
و 366.25Doyenne comicem rum - 355.62 (على التوالي. اما باقي الأصناف فقد كان حالة وسطية بين الاثثين و Conference كما لوحظ وجود مسافات بينية أو فراغات بين الخلايا البرنكيمية في منطقة اللب في الساق للأصناف. Bonne Louise و و أما الصنفين Bbatefetel و و Doyenne comicem hardy فوصف بأنة صلد لا يحتوي على مسافات بينية بين خلاياه.

جدول(3) الصفات الكمية والنوعية للخشب واللحاء في الساق مقاسه (بالمايكروميتر).

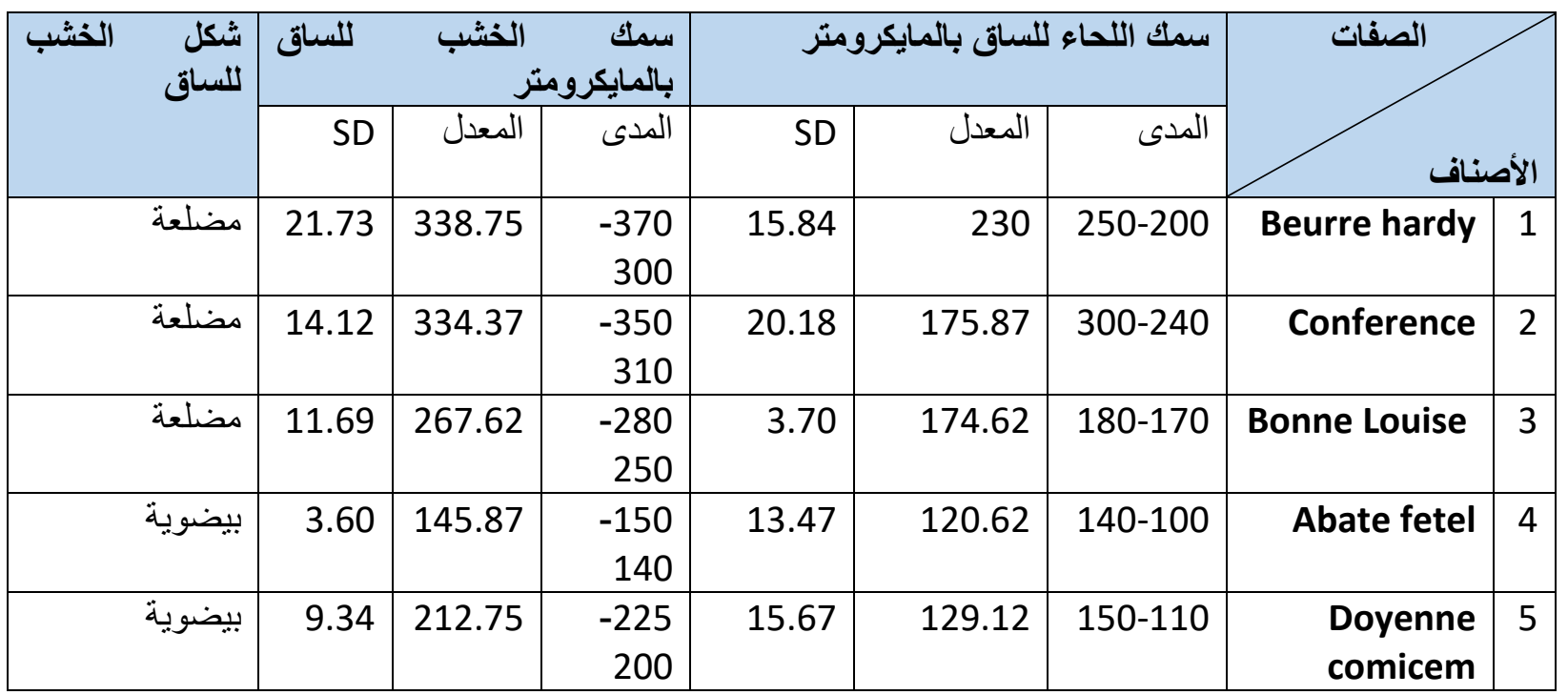


امنة احمد يحيى دلال باشي

كما تم التعرف على عدد الحزم لسيقان الأصناف الدروسة اذ حقق الصنف Bonne Louise اعلى عدد للحزم للساق (54)

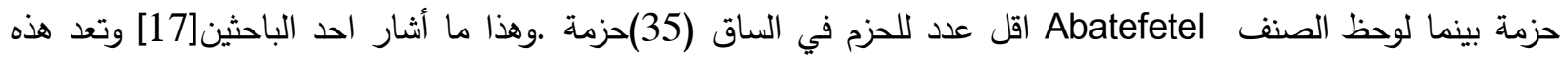
الصفات ذات أهمية تصنيفية عالية وذلك لأنها تعد من الصفات الوراثية الثابتة امام الظروف البيئية الدحيطة بها.

جدول (4): الصفات الكمية والنوعية للحزم الوعائية واللب في المقطع المستعرض لساق أصناف الكمثى قيد الدراسة مقاسه( بالمايكروميتر).

\begin{tabular}{|c|c|c|c|c|c|c|c|c|}
\hline \multicolumn{3}{|c|}{ علد الحزم في المقطع } & \multirow[t]{2}{*}{ شكل اللب } & \multicolumn{3}{|c|}{ قطر اللب للساق بالمايكروميتر } & \multirow[t]{2}{*}{ الصفات } & \\
\hline $\begin{array}{r}\text { SD } \\
\pm \\
\end{array}$ & المعدل & المدى & & $\begin{array}{r}\text { SD } \\
\pm \\
\end{array}$ & 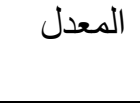 & المدى & & \\
\hline 2.61 & 44 & $40-48$ & صلا & 19 & 517.37 & $\begin{array}{r}552- \\
500\end{array}$ & Beurre hardy & 1 \\
\hline 2.12 & 52 & $49-54$ & على فتراغات & 11.33 & 412.50 & $\begin{array}{r}430- \\
400 \\
\end{array}$ & Conference & 2 \\
\hline 2.87 & 55 & 50-59 & على فترّاغات & 19.46 & 464.75 & $\begin{array}{r}490- \\
435 \\
\end{array}$ & $\begin{array}{l}\text { Bonne } \\
\text { Louise }\end{array}$ & 3 \\
\hline 3.06 & 35 & 30-39 & يحتى فرّاغات & 16.20 & 366.25 & $\begin{array}{r}390- \\
340 \\
\end{array}$ & Abate fetel & 4 \\
\hline 2.12 & 57 & $54-60$ & صلد & 14.74 & 355.62 & $\begin{array}{r}375- \\
330 \\
\end{array}$ & $\begin{array}{l}\text { Doyenne } \\
\text { comicem }\end{array}$ & 5 \\
\hline
\end{tabular}


استخام الصفات التثريحية للسيقان في تثخيص خمسة أصناف من نبات الكمثرى الإيطالية ...

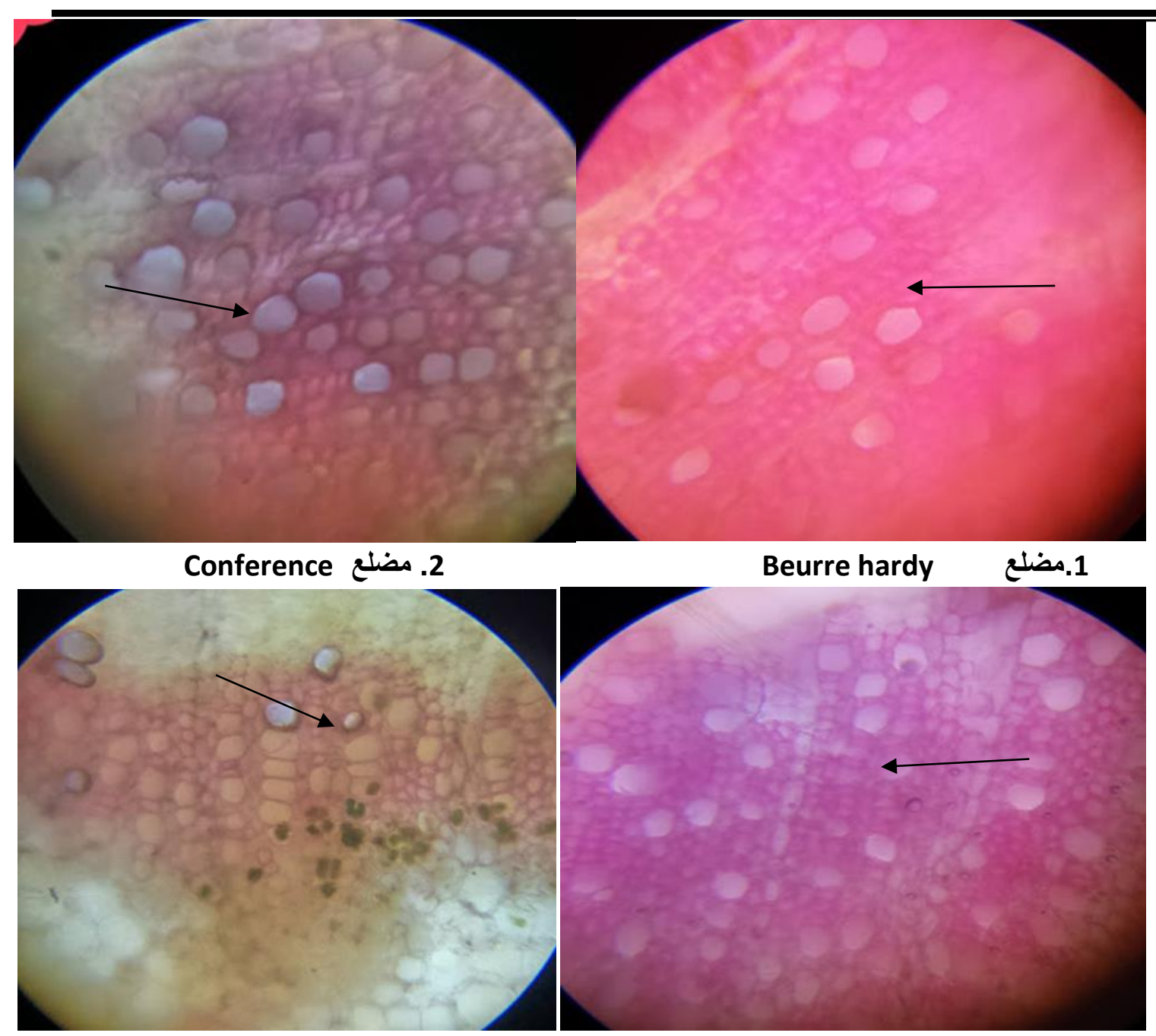

Abate fetel مضلع

Bonne louise بيضوي

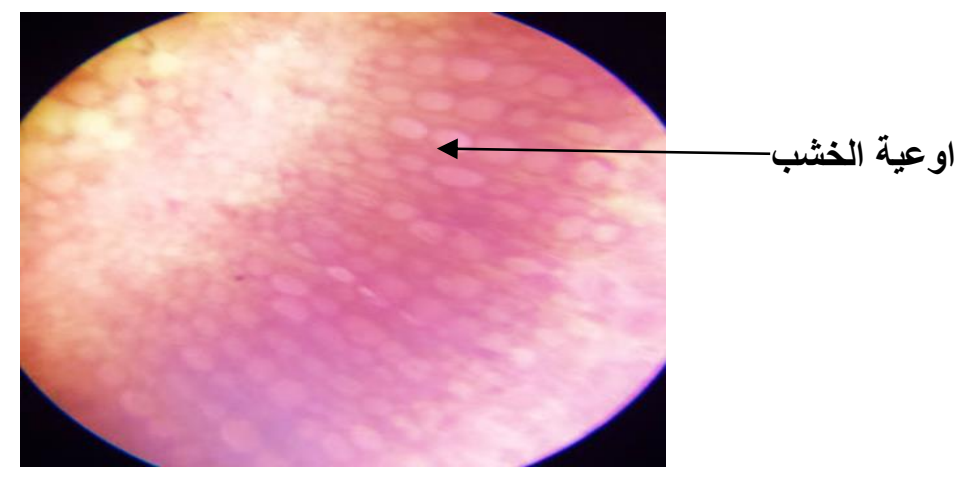

5oyenne comicem بيضوي

لوحة (4) يوضح اوعية الخثب في ساق نبات الكمثرى (قوة تكبير 400) 


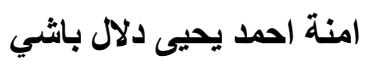

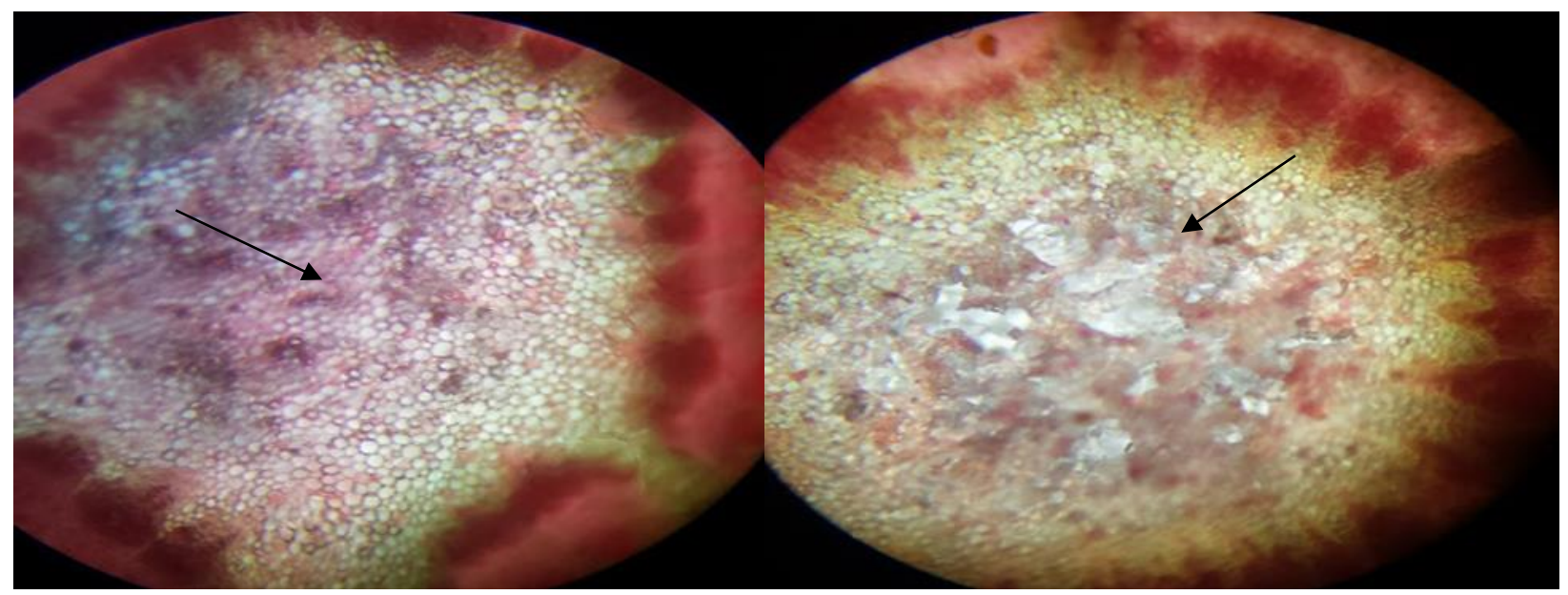

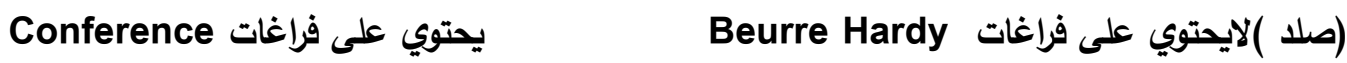

Bonne Louise

Doyenne Comicem

Abate Fetel

لوحة(5) يوضح شكل مركز الساق اللب لنبات الكثرى.( قوة تكبير 100)

المصادر

1. Al-Talib N.N.Y., M.Sc. Thesis college of Eduucation. University of Mosul.(2011)(In arabic)

2. AL.Burmani A.H, Marza T.H and Al-Nu'man R.M. Uni. Karb. Scie. Jou. 5:(2)396-403 (2007).(In arabic)

3.Zhang S.Y. Blumea ,37:81-158(1992)

4. AL.Moussawi A.H., "Plant Classification Science".1nd ED Baghdad University. 223-224 (1987) (In arabic)

5. Mahmoud A.M, Al-Moussawi A.H, Kassir W.A. Edu. and Sci., 17(3)69-79(2005) (In arabic)

6. Harlow W.M. and Harrar E.S. "Text book of Dendrology" ,8th ed.Mc Gram Hill,Co. New York 520.(1996).

7. Hancock J.F., Lobos G.A." Temperate Fruitcrop Breeding Library of congress" . Corvallis Oregon 299 -337(2008).

8.Hassoun S.M. University of kufa Jou. of Life Sci. 3, NO(1)1-20 (2011). (In arabic) 


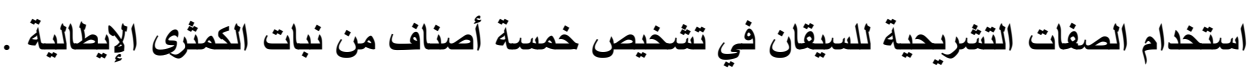

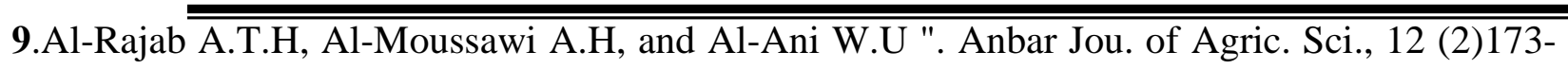
181(2014) (In arabic)

10. Al-Hadithi M.A, Al-Anbari A.K, Shalash H.M. Ibn Al-Haytham Jou. of Pure and Applied Sci., 29(3) 304-314(2016). (In arabic)

11.Al-Tamimi H.J.M. University of Karbala Sci. Jou. 6 (1) 96-110.(2008) (In arabic)

12.Akḉin, Ö. E., Yaḉin N. Turk Jou. Bot. ,28, 435-442.(2004) .

13.Revish N. M.R. Thiqar Jou., 8 (1) 148-156.(2012) (In arabic)

14. Al-Hadeethi M.A, Al-Obaidi B.M, Hamadi S.S, Al-Rikabi R.H. Ibn Al-Haitham Jou. for Pure \& Appl. Sci .2(2) 320-330 (2016) (In arabic)

15. Abu Siraj N.A.M. Jou. of Babylon University / Pure and Applied Sci.": 22,(1)1-18.(2012) (In arabic)

16. AL.Moussawi A.H, AL.Mashhadani A.N, NasrallahE.K, .Third Scientific Conference of University of Sci.Baghdad University.1227-1237(2009) (In arabic)

17. DahanT.E.S.,M.Sc. Thesis Faculty of Applied and Engineering Sci., Umm Al Qura University, Saudi Arabi(2009) (In arabic) 